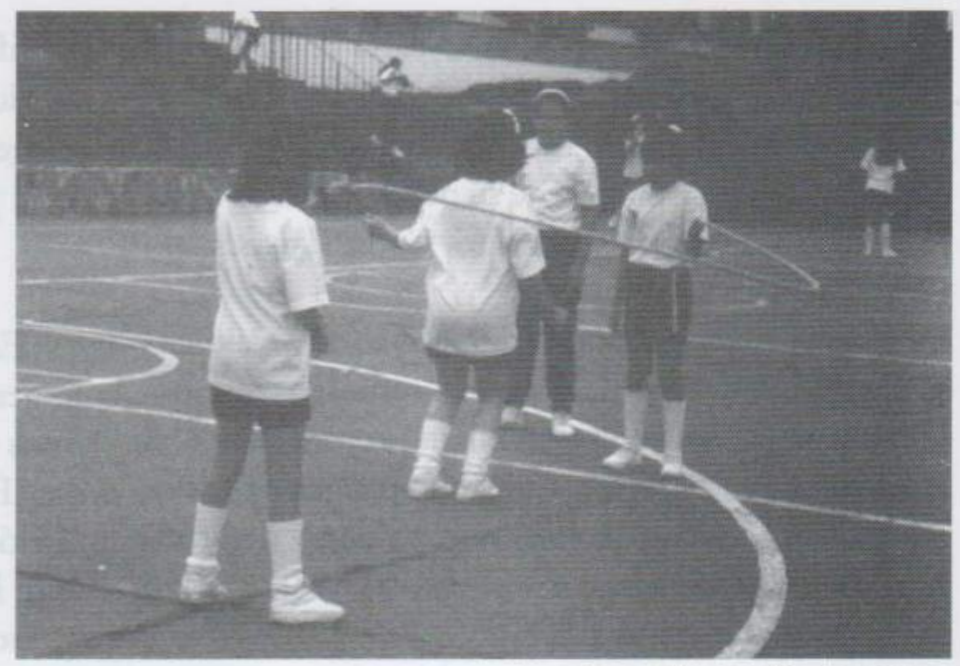

Por: Claudia Rocío Prieto

\title{
La práctica pedagógica y didáctica
}

OSCAR BERNAL*

Por práctica pedagógica y didáctica (PPD), se entiende, dentro del plan de estudios de 1984, como aquel espacio académico y experimental en donde el estudiante de educación física debe aplicar, a través de un proyecto pedagógico o investigativo, los conocimientos adquiridos durante los primeros seis semestres. Éste proyecto, que es, también de grado, se desarrolla en los semestres séptimo, octavo y noveno.

En la Facultad de Educación Física de la Universidad Pedagógica Nacional, la PPD, desde hace cuatro años, aproximadamente, entró en una dinámica más colectiva y realista. Colectiva porque busca organizar grupos de trabajo más integrados entre docentes, asesores y estudiantes, para salirse un poco del esquema uno: un profesor por alumno, y un proyecto de grado por alumno, y realista porque su interés se centra en proponer proyectos que respondan mejor a las necesidades educativas y pedagógicas de la comunidad educativa.

La nueva dinámica de la PPD pretende orientar los proyectos para que adquieran un carácter más investigativo: uno a nivel de investigación formativa, y otro que se aborde como investigación formal con una mayor cobertura; regional, nacional o internacional. Éstos últimos deben ser avalados por las instancias respectivas de la Universidad como el Centro de Investigaciones de la Universidad Pedagógica Nacional, CIUP, en su función de orientador de las políticas sobre investigación educativa, y COLCIENCIAS ${ }^{1}$, como el ente gubernamental que avala, promociona y evalúa la investigación en el ámbito nacional.

Algunos avances como fruto de esta experiencia se relacionan en la sección artículos de investigación científica y desarrollo, de éste número, y a continuación, se presentan otros dos, a manera de raes.

\footnotetext{
* Profesor de la Facultad de Educación Física, coordinador de la práctica. Universidad Pedagógica Nacional.

1. Instituto Colombiano Para el Fomento de la Ciencia y la Tecnología.
} 